$$
\begin{aligned}
& \text { NASA-TM-106096 } \\
& \text { Conf }-930103--47
\end{aligned}
$$

\title{
Radiation and Temperature Effects on Electronic Components Investigated Under the CSTI High Capacity Power Project
}

Gene E. Schwarze

National Aeronautics and Space Administration

Lewis Research Center

Cleveland, Ohio

Janis M. Niedra

Sverdrup Technology, Inc.

Lewis Research Center Group

Brook Park, Ohio

Albert J. Frasca

Wittenburg University

Springfield, Ohio

and

William R. Wieserman

University of Pittsburgh at Johnstown

Johnstown, Pennsylvania

Prepared for the

Tenth Symposium on Space Nuclear Power and Propulsion

sponsored by the University of New Mexico

Albuquerque, New Mexico, January 10-14, 1993 


\section{DISCLAIMER}

This report was prepared as an account of work sponsored by an agency of the United States Government. Neither the United States Government nor any agency Thereof, nor any of their employees, makes any warranty, express or implied, or assumes any legal liability or responsibility for the accuracy, completeness, or usefulness of any information, apparatus, product, or process disclosed, or represents that its use would not infringe privately owned rights. Reference herein to any specific commercial product, process, or service by trade name, trademark, manufacturer, or otherwise does not necessarily constitute or imply its endorsement, recommendation, or favoring by the United States Government or any agency thereof. The views and opinions of authors expressed herein do not necessarily state or reflect those of the United States Government or any agency thereof. 


\section{DISCLAIMER}

Portions of this document may be illegible in electronic image products. Images are produced from the best available original document. 


\title{
RADIATION AND TEMPERATURE EFFECTS ON ELECTRONIC COMPONENTS INVESTIGATED UNDER THE CSTI HIGH CAPACITY POWER PROJECT
}

\author{
Gene E. Schwarze \\ National Aeronautics \\ and Space Administration \\ Lewis Research Center \\ Cleveland, $\mathrm{OH} 44135$ \\ Albert J. Frasca \\ Wittenberg University \\ Springfield, $\mathrm{OH} 45501$
}

\author{
Janis M. Niedra \\ Sverdrup Technology, Inc. \\ Lewis Research Center Group \\ Brook Park, OH 44142
}

\author{
William R. Wieserman \\ University of Pittsburgh at Johnstown \\ Johnstown, PA 15904
}

\begin{abstract}
$\underline{\text { Abstract }}$
The effects of nuclear radiation and high temperature environments must be fully known and understood for the electronic components and materials used in both the Power Conditioning and Control subsystem and the reactor Instrumentation and Control subsystem of future high capacity nuclear space power systems. This knowledge is required by the designer of these subsystems in order to develop highly reliable, long-life power systems for future NASA missions. A review and summary of the experimental results obtained for the electronic components and materials investigated under the power management element of the CSTI high capacity power project will be presented in this paper: (1) Neutron, gamma ray, and temperature effects on power semiconductor switches, (2) Temperature and frequency effects on soft magnetic materials; and (3) Temperature effects on rare earth permanent magnets.
\end{abstract}

\section{INTRODUCTION}

The Civilian Space Technology Initiative (CSTI) is a NASA program designed to develop specific technologies in the areas of Space Transportation, Operations, and Science. High Capacity Power (HCP), initially an element of Operations, is presently included in the Planetary Surface Element. The goal of HCP is to develop the specific technologies required to meet the long duration, high capacity power requirements for future NASA lunar and planetary surface operations.

The High Capacity Power Project is divided into several subelements that includes Power Conversion, Advanced Materials, Thermal Management, Power Management, System Diagnostics, and Environmental Interactions. A recent overview of the CSTI High Capacity Power Project was given by Winter, et al., (1992). The focus of this paper will be on the Power Management subelement which is generally referred to as Power Management and Distribution (PMAD). 
PMAD can be broadly described as the conditioning and control of unregulated power from the Power Conversion subsystem and its transmission to a regulated power bus for distribution to the intended loads. The goal of the PMAD subelement is to develop, test, and demonstrate radiation-resistant, high temperature power and control components and circuits required in the Power Conditioning, Control, and Transmission (PCCT) subsystem of a space nuclear power system. The results obtained are also applicable to the Instrumentation and Control (I\&C) subsystem of a space nuclear reactor. These components and circuits must meet low mass and high efficiency requirements and operate reliably in a harsh nuclear radiation and high temperature environment for lifetimes of 7-10 years. Radiation tolerant components will reduce shielding requirements and circuit complexity. A reduction in shielding mass decreases system mass. A decrease in circuit complexity decreases component count and causes efficiency and reliability to increase. High temperature tolerant components will reduce the power electronics' radiator mass and volume. Power magnetic components operating at low frequency are massive so operation at high frequency will cause significant mass reductions in these components.

The PMAD work for the CSTI High Capacity Power Project is presently concentrated on the following tasks: (1) Radiation and temperature effects on semiconductor power switches, (2) Temperature and frequency effects on soft magnetic materials, (3) Temperature and aging effects on rare earth permanent magnets, and (4) Power Conditioning and Control for a Free-Piston Stirling power converter. The objective, approach, and summary of present results obtained for tasks 1,2 , and 3 will now be discussed.

\section{Power Semiconductor Radiation Effects Task}

The objective of this task is to experimentally determine and assess both the separate and combined effects of neutrons, gamma rays, and temperature on commercial, developmental, and research-type power semiconductor switches. The approach is to conduct in-situ experiments to measure the sensitivity of the switch's electrical and switching characteristics to gamma rays and neutrons for different bias conditions at room temperature with postirradiation thermal anneals, and also at elevated temperatures to assess the effects of possible self-annealing of radiation damage. The facilities used to conduct this research include Wittenberg University, NASA Lewis Research Center (LeRC), Ohio State University Reactor Facility, and the University of Cincinnati Co-60 Facility.

The type of semiconductor switches included in this test program are diodes, transistors, and thyristors. The transistors include the Bipolar Junction Transistor (BJT) and the Darlington, the Metal-Oxide-Semiconductor Field Effect Transistor (MOSFET), the Static Induction Transistor (SIT), which is a power type Junction FET (JFET), and the Insulated Gate Bipolar Transistor (IGBT). The thyristors include both the phase-control and inverter type Semiconductor Controlled Rectifier (SCR), and the MOS Controlled Thyristor (MCT).

The effects of neutrons and gamma rays on a semiconductor crystal will first be briefly reviewed, followed by a summary of how these types of radiation affect the electrical and switching characteristics of some of the different types of switches listed above. In general, 
high energy nuclear radiation incident on a semiconductor crystal is absorbed in the material by two mechanisms: atomic collisions and electronic ionization. The relative importance of the two mechanisms depends on the type of radiation and the type of semiconductor device.

Collisions occur between the incident high energy particles and atoms of the crystal, and also subsequent collisions between the recoiling atom and other atoms of the crystal. The mechanism of collisions results in atomic displacement damage if the recoiling atom receives sufficient energy to be displaced from its equilibrium site in the crystal lattice. Displacement of an atom in silicon requires about $15-25 \mathrm{eV}$ of energy to be transferred from the incident particle to the target atom. Atomic disorder or displacement damage causes the formation of simple defects such as vacancy-interstitial pairs, or more complex defects known as "clusters," which are isolated regions in the lattice structure containing large quantities of displaced atoms. The radiation induced displacement damage is dependent on the type, energy, direction, and quantity of the incident particles; type and concentration of impurities and defects existing in the crystal prior to irradiation; and irradiation conditions such as crystal temperature.

The radiation induced defects caused by displacement of atoms affects the electrical properties of the semiconductor by the formation of energy levels in the intrinsic semiconductor's energy bandgap. Shallow induced energy levels will act as donors or acceptors depending on how close these levels are to either the conduction or valence band, respectively. Deep energy levels will act as recombination-generation (R-G) centers and are sometimes called deep level traps. The introduction of R-G centers in a semiconductor introduces an additional mechanism to reduce the lifetime of a minority carrier wandering about in majority carrier territory. An increase in radiation induced defects causes an increase in R-G center density and this causes a decrease in minority carrier lifetime and an increase in R-G rates. Radiation damage caused by atomic displacements also alters the periodicity of the crystal lattice, and the displaced atoms act as carrier scattering centers to cause a decrease in carrier mobility.

The interaction of fast neutrons with a semiconductor material is primarily by collisions between the nucleus of an atom and the incident neutron, followed by collisions of the recoiling atoms with other atoms. Fast neutrons primarily cause displacement damage that alters the semiconductor's bulk electrical properties which includes minority carrier lifetime, carrier mobility, and carrier concentration. Fast neutrons also cause ionization, but their predominant effect in semiconductor materials is to cause radiation induced R-G centers via collisions with atomic nuclei.

The interaction of energetic gamma rays with a semiconductor material is primarily by Compton scattering that causes ionization of the material's atoms. This scattering causes either excitation of orbital electrons or the production of electron-hole pairs. An ionized electron imparted with sufficient kinetic energy can cause either additional ionization, or impart sufficient energy to an atom to cause its displacement. Energetic gamma rays can generate R-G centers through displacement effects, but not as effectively as fast neutrons. 
The effects of neutrons and gamma rays and subsequent post-irradiation thermal anneals on the electrical and switching characteristics of NPN BJTs have been reported by Frasca and Schwarze $(1988,1991)$. One of the BJTs tested was the D60T455010 (450 V/50 A) for neutron fluences up to $1.6 \times 10^{13} \mathrm{n} / \mathrm{cm}^{2}$ and gamma doses up to 4.9 Mrads. The BJTs were found to be most sensitive to neutrons which caused rapid degradation in the commonemitter dc current gain $\left(\mathrm{h}_{\mathrm{FE}}\right)$ and an attendant decrease in the switching storage time. Both of these decreases are traceable to a reduction in the minority carrier lifetime. Neutrons also caused an increase in leakage current, but whether this increase was due to bulk semiconductor or surface effects was not firmly established. The BJTs were found to be relatively insensitive to gamma rays up to 0.5 Mrads, after which $h_{\mathrm{FE}}$ began to decrease gradually. Figure 1 shows $h_{\mathrm{FE}}$ as a function of collector current at a collector-emitter voltage of $2.5 \mathrm{~V}$ for pre- and post-irradiation along with post-irradiation thermal anneals to $425 \mathrm{~K}$ for a D60T455010. The thermal annealing results clearly indicate that the severe degradation in $\mathrm{h}_{\mathrm{FE}}$ caused by neutrons at an irradiation temperature of $300 \mathrm{~K}$ is permanent for thermal anneals up to $425 \mathrm{~K}$ because these anneals had little effect in restoring $h_{\mathrm{FE}}$ to its pre-irradiation condition.

The effects of neutrons and gamma rays and subsequent post-irradiation thermal anneals on the electrical characteristics of $\mathrm{N}$-channel enhancement mode MOSFETs have been reported by Frasca and Schwarze $(1989,1991)$. One of the devices tested was the MTM15N50 (500 V/15 A) for neutron fluences up to $3.8 \times 10^{13} \mathrm{n} / \mathrm{cm}^{2}$ and gamma doses up to 1.5 Mrads. The MOSFETS were most sensitive to gamma rays and their effect on the gate-source threshold voltage $\mathrm{V}_{\mathrm{GS}(\mathrm{th})}$ is shown in Figure 2. It should be noted that the type of bias applied to the gate-source during irradiation does affect the rate of change of $\mathrm{V}_{\mathrm{GS}(\mathrm{th})}$ with gamma dose. The results in Figure 2 are for the condition where the gate, source, and drain terminals are all floating during irradiation. Gamma rays generate electron-hole pairs in the gate oxide and the result is that some of the holes are captured by traps at the oxidesemiconductor interface to cause a positive charge build-up in the oxide. This causes a negative shift in $V_{G S(t h)}$ so that a less positive gate bias is required for turn-on. Sufficient positive charge build-up can cause $\mathrm{V}_{\mathrm{GS}(\mathrm{th})}$ to be equal to or less than zero, as clearly demonstrated by the results shown in Figure 2. For $\mathrm{V}_{\mathrm{GS}(\mathrm{th})} \leq 0$, the $\mathrm{N}$-channel enhancement mode MOSFET behaves like an N-channel depletion mode MOSFET because turn-on occurs with application of positive drain-source voltage and a negative gate bias is required for turn-off and maintenance of the off-state. Post-irradiation thermal anneals up to $425 \mathrm{~K}$ caused only a small recovery in $\mathrm{V}_{\mathrm{GS}(\text { th })}$ to its pre-irradiation condition. The MOSFETs neutron irradiated were found to be quite insensitive to fluences up to $10^{13} \mathrm{n} / \mathrm{cm}^{2}$. Beyond this level, the drain-source resistance was found to increase rapidly with fluence.

The effects of neutron fluences to $5.1 \times 10^{13} \mathrm{n} / \mathrm{cm}^{2}$ and gamma doses to $1.8 \mathrm{Mrads}$ and subsequent post-irradiation thermal anneals on the electrical characteristics of $\mathrm{N}$-channel SITs have been reported by Frasca and Schwarze $(1990,1991)$. The device tested was the 2SK180 (600 V/8 A). The SIT is a normally-on device, that is, a negative gate bias is required for turn-off and maintenance of the off-state. A positive gate bias causes conductivity modulation of the drift region with the result being a considerable decrease in the drain source on-resistance $\left(\mathrm{R}_{\mathrm{DS}(\mathrm{ON})}\right)$. The SITs were found to be neither sensitive to neutrons nor gamma rays for neutron fluences to $10^{13} \mathrm{n} / \mathrm{cm}^{2}$ and gamma doses to 0.5 Mrads, 
respectively. No significant increases in $R_{D S(O N)}$ was observed for gamma doses up to 1.8 Mrads. However, as shown in Figure 3, $R_{\mathrm{DS}(\mathrm{ON})}$ begins to show a significant increase for fluences beyond $10^{13} \mathrm{n} / \mathrm{cm}^{2}$. A $425 \mathrm{~K}$ post-irradiation thermal anneal had no significant effect on $R_{\mathrm{DS}(\mathrm{ON})}$. Thus, the neutron induced damage in SITs irradiated at $300 \mathrm{~K}$ is quite stable because the damage sites remain immobile for annealing temperatures up to $425 \mathrm{~K}$.

Frasca and Schwarze (1992) have reported on the effects of neutrons and gamma rays on phase-control and inverter type SCRs. The C38E (500 V/35 A) phase-control SCRs were neutron and gamma irradiated up to $3.1 \times 10^{13} \mathrm{n} / \mathrm{cm}^{2}$ and 5.1 Mrads, respectively and the 20RIF40W20 (400 V/32 A) inverter-type SCRs were neutron and gamma irradiated up to $3.2 \times 10^{13} \mathrm{n} / \mathrm{cm}^{2}$ and 5.1 Mrads, respectively. For both types of SCRs, the neutron irradiations were done at 300 and $425 \mathrm{~K}$, while the gamma irradiations were done only at $300 \mathrm{~K}$. The most significant results of the effects of neutrons and gamma rays on both types of SCRs were as follows: (1) Neutron fluences beyond $10^{13} \mathrm{n} / \mathrm{cm}^{2}$ caused the on-state forward voltage drop $\left(\mathrm{V}_{\mathrm{F}}\right)$ to increase sharply regardless of irradiation temperature and this effect is shown in the plot of $V_{F}$ versus fluence in Figure 4; (2) The reverse and forward leakage currents increased at a faster rate for the devices irradiated at $365 \mathrm{~K}$ than those irradiated at $300 \mathrm{~K}$ so that here a higher irradiation temperature had a detrimental rather than a beneficial effect; (3) Neutron fluences of $3 \times 10^{13} \mathrm{n} / \mathrm{cm}^{2}$ caused a 40-fold decrease in the turn-off time $\left(t_{q}\right)$ of the phase-control SCR, and (4) Gamma ray doses up to 5.1 Mrads caused insignificant increases in $\mathrm{V}_{\mathrm{F}}$, small increases in leakage currents, and up to a 62\% decrease in $t_{q}$ of the phase-control SCRs. The increase in $V_{F}$ and decrease in $t_{q}$ are traceable to a reduction in the minority carrier lifetime. The cause for the increase in leakage currents was not firmly established as to whether these were bulk or surface effects.

In summary the following conclusions can be made with regard to the results obtained: (1) The device type and type of radiation determines the degradation rate of the devices's electrical and switching characteristics; (2) Each of the devices discussed above was still operational after being exposed to a minimum neutron fluence of $10^{13} \mathrm{n} / \mathrm{cm}^{2}$ and gamma dose of 0.5 Mrads, which are the SP-100 requirements for the electronics at $25 \mathrm{~m}$ from the nuclear source. Although the switches were still operational, one or more of the switch's parameters was definitely affected by either the neutrons or gamma rays; (3) Even though all devices tested were operational up to SP-100 specifications, all candidate devices must be thoroughly tested in operating circuits under dynamic conditions for the intended radiation and temperature environments in order to clearly identify all operational failure modes; (4) All the devices discussed use silicon (Si) technology. A semiconductor material other than Si will be required for neutron fluences greater than $10^{13} \mathrm{n} / \mathrm{cm}^{2}$ and (5) Improvements are needed in gate oxides and interface state defects for gamma doses exceeding $1 \mathrm{Mrad}$.

As noted above, all the power devices investigated to date utilized silicon technology. A newly emerging, and very promising semiconductor technology is silicon carbide (SiC). This semiconductor material offers the real possibility of high temperature ( $>475 \mathrm{~K}$ ) power semiconductors, something that cannot be achieved by presently available silicon semiconductor switches. SiC semiconductors also offer the possibility of a much higher tolerance to radiation damage. As $\mathrm{SiC}$ devices become available, they will be experimental- 
ly investigated for both their temperature and radiation damage tolerance.

\section{Soft Magnetic Materials Task}

The designer of power magnetic components such as transformers, inductors, motors, generators, etc., requires specific knowledge about the electrical and magnetic properties of the magnetic materials used in these components. The dc magnetic properties, such as the "static" B-H hystersis loop, are very useful as a guide for comparing different types of magnetic materials, but it is the ac magnetic and electrical properties which primarily determine the usefulness of a magnetic material for a particular application. One of the most important ac properties required by the designer is the core loss (power dissipated in the magnetic material) as a function of magnetic flux density $\left(\mathrm{B}_{\mathrm{m}}\right)$, frequency ( $f$ ), temperature $(T)$, and type of excitation and its waveform. In addition, the effects of temperature cycling and long term stability and aging must also be known. Dynamic or ac B-H loops, or their decomposition into flux and current excitation versus time waveforms, are also of interest because they give such information as saturation magnetization, coercivity, remanence, and loop stability under cyclic conditions. The size of the dynamic loop gives an excellent qualitative assessment of the core loss, and the shape of the loop gives insight into stability characteristics such as the presence of any dc offsets.

A study (Schwarze, Niedra, and Wieserman 1991) of previous experimental investigations of soft magnetic materials was conducted prior to initiation of the present program. This study clearly showed a sparsity of electrical and magnetic data for the combined conditions of high temperature and high frequency. To address this need, the NASA LeRC initiated an experimental program to characterize candidate soft magnetic materials over a wide range of temperatures for a wide range of frequencies for different types of excitation.

The objective of the soft magnetic materials task is to experimentally determine the combined effects of temperatures up to $575 \mathrm{~K}$ and frequencies up to $50 \mathrm{kHz}$ on the electrical and magnetic characteristics of selected commercially available materials, and to conduct comparison studies of the data to determine which materials gives the best performance for a given temperature and frequency range. The approach is to first characterize candidate soft magnetic materials for this temperature and frequency range under sinusoidal voltage excitation and then, based on these results, select candidate materials to characterize under non-sinusoidal voltage excitation, with particular emphasis on square wave voltage excitation. The research facilities of the University of Pittsburgh at Johnstown, and NASA LeRC are used to conduct these tests and analyze and evaluate the experimental results.

The various types of soft magnetic materials can be conveniently grouped as follows: Alloys of iron and silicon containing 0.5 to $6 \%$ silicon; alloys of iron and nickel with or without a third element such as molybdenum, chromium, silicon, or copper; alloys of nickel and cobalt; alloys of iron and cobalt with or without a third element such as vanadium or chromium; alloys of iron, cobalt, and nickel; ferrites; and the relatively new class of amorphous magnetic materials. For crystalline materials, the iron-cobalt alloys have the highest Curie temperature, and also the highest saturation flux density while nickel-iron 
alloys with a high percentage of nickel, have the lowest Curie temperature and the lowest saturation flux density. However, from this, one should not conclude that only the ironcobalt alloys are acceptable for high temperature operation because for operating temperatures below $575 \mathrm{~K}$, the high percentage nickel-iron alloys for example, could give superior performance in terms of core loss at high frequencies. Thus, the operating frequency, excitation, temperature, and mass and efficiency requirements, will determine which magnetic material is most suitable for a specific application.

The soft magnetic materials investigated to date for sinewave voltage excitation are listed in Table 1 which includes the test frequency and temperature ranges. The experimental results and a comparison of core loss for Supermalloy, Metglas 2605SC and Metglas 2605S$3 A$ have been reported by Wieserman, Schwarze, and Niedra $(1990,1991)$. These experimental results show that Metglas 2605SC can not compete with either Metglas 2605S-3A or Supermalloy in terms of core loss for the frequency and temperature range given in Table 1. However, Metglas 2605-3A can compete with Supermalloy in the 425 to $575 \mathrm{~K}$ range because in this temperature range the core loss for that Metglas is equal to or less than that for Supermalloy. A comparison of the core loss for Orthonol, 48 Alloy, and Metglas 2605SC has been reported by Wieserman, Schwarze, and Niedra (1991). They found that for these three alloys, 48 Alloy tends to have the lowest core loss over the temperature range of 300 to $575 \mathrm{~K}$ and frequency range of 1 to $50 \mathrm{kHz}$ except at $300 \mathrm{~K}$ for all frequencies, where Metglas 2605SC gave a lower core loss. In their investigation of Magnesil and Supermendur, Wieserman, Schwarze, and Niedra (1992) found that Supermendur had the lowest core loss for high flux densities for frequencies of $400 \mathrm{~Hz}$ and less over the temperature range of 300 to $575 \mathrm{~K}$; otherwise Magnesil had lower core loss in the frequency range of 1 to $10 \mathrm{kHz}$. However, a comparison of Magnesil and Supermendur core loss at $300 \mathrm{~K}$ after the $575 \mathrm{~K}$ exposure gave an unexpected result: for equivalent $\mathrm{B}_{\mathrm{m}}$ and $f$ values, Supermendur always had lower losses than Magnesil. Additional experimental investigations will be required to determine whether these low loss values for Supermendur would be retained if it were again temperature cycled to $575 \mathrm{~K}$. Thus, not only for these two alloys, but also for the other materials given in Table 1, the effects of both temperature cycling and long term aging must be carefully investigated. This is necessary so that a quantitative assessment can be made on the sensitivity of the magnetic and electrical properties to the effects of temperature cycling and long term aging. Presently, the focus of the work under this task is on the experimental investigation of several of the alloys listed in Table 1 for the condition of square wave voltage excitation for temperatures to $575 \mathrm{~K}$ and frequencies to $50 \mathrm{kHz}$. This square wave data will have specific application to the design of power magnetic components used in high frequency dc/ac inverters and dc/dc converters.

\section{Rare Earth Permanent Magnet Task}

The Stirling Space Power Converter (SSPC) being developed by NASA LeRC for space power applications uses rare earth permanent magnets as the excitation source in the linear alternator. These magnets are exposed to temperatures of $575 \mathrm{~K}$ and successful demonstration of this power converter requires that these magnets function reliably over a period of 7-10 years. Demagnetization of the magnets during operation would result in a complete loss of alternator output power. The need to minimize converter volume, mass, 
and losses requires that the magnets' capabilities be utilized to their limits.

Of the various available high-energy permanent magnet materials, only the $\mathrm{SmCo}_{5}$ and $\mathrm{Sm}_{2} \mathrm{Co}_{17}$ types can produce magnets retaining at $575 \mathrm{~K}$ a useful remanence and sufficiently high intrinsic coercivity to avoid self-demagnetization, and to keep the induction roughly linear with the applied field in the second quadrant of the M-H hysteresis loop. Among the well known demagnetizing influences of permanent magnets are an externally applied bucking field, thermal agitation of domains over their pinning potential barriers as well as thermally induced metallurgical change, mechanical shock, and possibly nuclear radiation effects. However, determining the characteristics of the samarium-cobalt type magnets under these demagnetizing influences does present some formidable challenges in instrumentation and measurement techniques. First, these modern samarium-cobalt magnets are not easily magnetized; the "charging" field pulse must exceed the magnet's intrinsic coercivity (usually tens of kiloersteds at room temperature) by at least a factor of 2 or 3 in order to develop the maximum possible coercivity. Further, at $575 \mathrm{~K}$ significant instrumentation problems related to thermal expansion of the magnet sample temperaturecontrol fixture, field-sensing coil expansion and wire insulation, and sample handling must be overcome. Such experimental difficulties have no doubt contributed to the scarcity of high temperature demagnetization data on otherwise promising high temperature magnets. To address the need for this data, the NASA LeRC initiated an in-house program to experimentally characterize and assess the effects of temperatures up to $575 \mathrm{~K}$ on candidate samarium-cobalt magnets. The development of this data base will enable the alternator designer to conduct comparison studies of the candidate materials in terms of performance limitations and then, select that magnet material which will meet the design requirements. It should be noted that this data base is also applicable to the design of permanent magnet motors, generators, traveling wave tubes, and other particle beam applications.

The objective of the high temperature rare earth permanent magnet characterization task has four main elements: (1) Design and develop (and upgrade as required) a high temperature test and calibration system to accurately measure, record, and plot the demagnetization characteristics of permanent magnets; (2) Experimentally determine the effects of temperature up to $575 \mathrm{~K}$ on the demagnetization characteristics of candidate samarium-cobalt permanent magnets; (3) Experimentally determine aging effects (loss in remanence and coercivity) as a function of temperature and time; and (4) Conduct comparison studies to determine which samarium-cobalt magnets are the least sensitive to temperature and aging effects.

The approach to accomplish this objective consists of two separate phases of investigation. In phase 1, the 2nd quadrant $\mathrm{M}-\mathrm{H}$ loops of $\mathrm{Sm}_{2} \mathrm{Co}_{17}$ and $\mathrm{SmCo}_{5}$ rare earth magnets will be experimentally measured and plotted for short-term conditions (less than 10 minutes at a given temperature) for temperatures up to $575 \mathrm{~K}$ to determine the changes in the magnet's remanence and coercivity properties as a function of temperature. In phase 2 , long-term elevated temperature tests up to $575 \mathrm{~K}$ will be conducted to determine the rate of degradation of the remanence and coercivity properties as a function of time and temperature. 
A permanent magnet measurements laboratory capable of conducting rare earth permanent magnet experimental investigations under short-term conditions up to $575 \mathrm{~K}$ has been developed at NASA LeRC and is fully operational. A complete description of the basic magnetic measurement instrumentation used in this laboratory along with the procedures and techniques used to obtain the data is given by Niedra and Schwarze (1991). The additional test equipment and instrumentation, special test fixtures, and environmental chambers required to conduct the long term aging tests for the conditions of either a zero or a specified applied bucking field at temperature are presently being implemented.

2nd quadrant M-H curves have been obtained for temperatures from 294 to $573 \mathrm{~K}$ for 10 sample groups of high intrinsic coercivity, anisotropic $\mathrm{Sm}_{2} \mathrm{Co}_{17}$ magnets from 5 manufacturers (Niedra 1992). Figure 5 illustrates the demagnetization characteristics for one of the specimens tested. The general observations from the test data for these magnets are as follows: (1) All samples exhibited the usual rapid loss of intrinsic coercivity and lesser loss of remanence as the temperature increased; (2) Room temperature M-H demagnetization curve shape varies considerably with sample source; (3) An increase in temperature tends to cause the M-H curve to become more "square"; (4) Room temperature data is not always a reliable indicator of performance at $573 \mathrm{~K}$; and (5) The $\mathrm{M}-\mathrm{H}$ curves were repeatable at all temperatures, indicating that the samples were fully magnetized and also the absence of any metallurgical aging effects for these short term tests.

A method was devised by Niedra and Overton (1991) to construct safe operating area (SOA) plots from the M-H demagnetization curves. Figure 6 gives the SOA plot for the magnet whose demagnetization characteristics are given in Figure 5. In this plot, the curve of the "knee point" field $\left(\left|{ }_{M} \mathrm{H}_{k}\right|\right)$ as a function of temperature, forms the boundary of the SOA. The point on the $\mathrm{M}-\mathrm{H}$ demagnetization curve in Figure 5 where $\mathrm{M}=0.9 \mathrm{M}_{\mathrm{r}}$ or "knee point", is conventionally taken as the point of onset of rapid downslope. Depending on the M-H curve squareness, an immediate and significant loss of magnetization can set in if the applied field drives $M$ below its knee point. This loss is then recoverable only by remagnetization. Superimposed on the plot in Figure 6 are curves showing, at a given temperature, the magnitude of the demagnetizing field $\left(\left|\mathrm{H}_{\mathrm{d}}\right|\right)$ needed to produce a desired induction swing $\triangle B$ below the remanence induction $\left(B_{r}\right)$; these curves are parametrized by $\Delta B / B_{r}$, where $B_{r}$ is at temperature. The peak $H_{d}$ is found from the constitutive relation $B$ $=\mathrm{H}+4 \pi \mathrm{M}(\mathrm{H})$ at temperature by setting $B=B_{r}-\Delta B$. Safe operation of the magnet requires that the $\left|\mathrm{H}_{d}\right|$ curve lies below the $\left|{ }_{M} \mathrm{H}_{k}\right|$ curve, that is $\left|\mathrm{H}_{d}\right|<\left|{ }_{M} \mathrm{H}_{k}\right|$. If this inequality becomes reversed for a particular induction swing $\Delta \mathrm{B}$ at a given temperature, then the magnet will become demagnetized. For example, Figure 6 shows that this magnet can be safely operated up to at most $523 \mathrm{~K}$ with $\Delta \mathrm{B}=\mathrm{B}_{\mathrm{r}^{\circ}}$. To achieve safe operation at $573 \mathrm{~K}$ would require that $\Delta \mathrm{B}<0.8 \mathrm{~B}_{\mathrm{r}}$. This type of SOA plot enables the alternator designer to very quickly determine what margin of safety must be incorporated into the design so that demagnetization effects caused by temperature do not cause a catastrophic operational failure of the alternator. 


\section{CONCLUSIONS}

An overview and summary are given of the experimental and analytical work conducted under the Power Management element of the CSTI High Capacity Power Project. The scope of this work has been limited to the investigation of nuclear radiation and temperature effects on power semiconductor switches, temperature and frequency effects on soft magnetic materials, and temperature effects on permanent magnets. The results obtained in these investigations should contribute to the knowledge and technical base needed to develop power generation and conditioning components for future NASA space missions. The effects of radiation and temperature on other power components and materials such as capacitors and electrical insulation certainly needs to be investigated in order to enable the design of long life, high reliability, low mass, and high efficiency PCC\&T and $\mathrm{I} \& \mathrm{C}$ subsystems in space nuclear power systems.

\section{Acknowledgments}

This work was sponsored by the NASA Lewis Research Center under the Power Management element of the High Capacity Power Project of the Civilian Space Technology Initiative.

\section{References}

Frasca, A. J. and G. E. Schwarze (1988) "Neutron Effects on the Electrical and Switching Characteristics of NPN Bipolar Power Transistors," in Trans. Fifth Symposium on Space Nuclear Power Systems, CONF-880122 -- Summs., held in Albuquerque, NM, 11-14 January 1988.

Frasca, A. J. and G. E. Schwarze (1989) "Neutron and Gamma Effects on the Electrical and Switching Characteristics of Power MOSFETs," in Trans. Sixth Symposium on Space Nuclear Power Systems, CONF-890 103 -- Summs., held in Albuquerque, NM, 8-12 January 1989.

Frasca, A. J. and G. E. Schwarze (1990) "Neutron and Gamma Effects on the Electrical and Switching Characteristics of Power Static Induction Transistors (SITs)," in Trans. Seventh Symposium on Space Nuclear Power Systems, held in Albuquerque, NM, 7-11 January 1990.

Frasca, A. J. and G. E. Schwarze (1990) "Neutron and Gamma Irradiation Effects on Power Semiconductor Switches," in Proc. 25th Intersociety Energy Conversion Engineering Conference, held in Reno, NV, 12-17 August 1990.

Frasca, A. J. and G. E. Schwarze (1991) "Effects of Thermal Annealing on Power BJTs, MOSFETs, and SITs following Neutron and Gamma Irradiation," in Proceedings Eighth Symposium on Space Nuclear Power Systems, CONF-910116, held in Albuquerque, NM, 6-10 January 1991. 
Frasca, A. J. and G. E. Schwarze (1992) "Neutron, Gamma Ray, and Temperature Effects on the Electrical Characteristics of Thyristors," in Proc. 27th Intersociety Energy Conversion Engineering Conference, held in San Diego, CA, 3-7 August 1992.

Niedra, J. M. and E. Overton (1991) " 23 to $300^{\circ} \mathrm{C}$ Demagnetization Resistance of Samarium-Cobalt Permanent Magnets," NASA Technical Paper 3119, October 1991.

Niedra, J. M. and G. E. Schwarze (1991) "Makeup and Uses of a Basic Magnet Laboratory for Characterizing High-Temperature Permanent Magnets," in Proceedings First International High Temperature Electronics Conference, held in Albuquerque, NM, 16-20 June 1991.

Niedra, J. M. (1992) "M-H Characteristics and Demagnetization Resistance of SamariumCobalt Permanent Magnets to $300^{\circ} \mathrm{C}$," in Proc. 27th Intersociety Energy Conversion Engineering Conference, held in San Diego, CA, 3-7 August 1992.

Schwarze, G. E., J. M. Niedra, and W. R. Wieserman (1991) "High Temperature, High Frequency Experimental Investigation of Soft Magnetic Materials," in Proceedings First International High Temperature Electronics Conference, held in Albuquerque, NM, 16-20 June 1991.

Schwarze, G. E. and A. J. Frasca (1991) "Neutron, Gamma Ray and Post-Irradiation Thermal Annealing Effects on Power Semiconductor Switches," AIAA 91-3525, AIAA/NASA/OAI Conference on Advanced SEI Technologies, held in Cleveland, $\mathrm{OH}$, 4-6 September 1991.

Wieserman, W. R., G. E. Schwarze, and J. M. Niedra (1990) "High Frequency, High Temperature Specific Core Loss and Dynamic B-H Hysteresis Loop Characteristics of Soft Magnetic Alloys," in Proc. 25th Intersociety Energy Conversion Engineering Conference, held in Reno, NV, 12-17 August 1990.

Wieserman, W. R., G. E. Schwarze, and J. M. Niedra (1991) "Comparison of High Frequency, High Temperature Core Loss and B-H Loop Characteristics of an $80 \mathrm{Ni}-\mathrm{Fe}$ Crystalline Alloy and Two Iron-Based Amorphous Alloys," in Proceedings Eighth Symposium on Space Nuclear Power Systems, CONF-910116 held in Albuquerque, NM, 610 January 1991.

Wieserman, W. R., G. E. Schwarze, and J. M. Niedra (1991) "Comparison of High Temperature, High Frequency Core Loss and Dynamic B-H Loops of Two $50 \mathrm{Ni-Fe}$ Crystalline Alloys and an Iron-Based Amorphous Alloy," in Proc. 26th Intersociety Energy Conversion Engineering Conference, held in Boston, MA, 4-9 August 1991.

Wieserman, W. R., G. E. Schwarze, and J. M. Niedra (1992) "Comparison of High Temperature, High Frequency Core Loss and Dynamic B-H Loops of a $2 \mathrm{~V}-49 \mathrm{Fe}-49 \mathrm{Co}$ and a Grain Oriented 3 Si-Fe Alloy," in Proc. 27th Intersociety Energy Conversion Engineering Conference, held in San Diego, CA, 3-7 August 1992. 
Winter, J. M., et al., (1992) "The NASA CSTI High Capacity Power Project," in Proc. 27th Intersociety Energy Conversion Conference, held in San Diego, CA, 3-7 August 1992.

TABLE 1. Soft Magnetic Materials Experimentally Characterized for Sinewave Voltage Excitation

\begin{tabular}{|c|c|c|c|c|c|}
\hline \multirow[b]{2}{*}{ Material } & \multirow[b]{2}{*}{ Nominal Composition } & \multirow[b]{2}{*}{$\begin{array}{c}\text { Saturation } \\
\text { Flux Density }(\mathrm{T})\end{array}$} & \multirow[b]{2}{*}{$\begin{array}{c}\text { Curie } \\
\text { Temp. (K) }\end{array}$} & \multicolumn{2}{|c|}{ Test Conditions } \\
\hline & & & & $\begin{array}{c}\text { Frequency } \\
\text { Range }\end{array}$ & $\begin{array}{c}\text { Temperature } \\
\text { Range }\end{array}$ \\
\hline & & Crystalline Alloys & & & \\
\hline Supermalloy & $80 \mathrm{Ni}-15 \mathrm{Fe}-5 \mathrm{Mo}$ & 0.8 & 675 & $1.50 \mathrm{kHz}$ & $300-575 \mathrm{~K}$ \\
\hline Orthonol & $50 \mathrm{Ni}-50 \mathrm{Fe}$ & 1.6 & 795 & $1-50 \mathrm{kHz}$ & $300-575 \mathrm{~K}$ \\
\hline 48 Alloy & $50 \mathrm{Ni}-50 \mathrm{Fe}$ & 1.6 & 795 & $1.50 \mathrm{kHz}$ & $300-575 \mathrm{~K}$ \\
\hline Magnesil & $3 \mathrm{Si}-97 \mathrm{Fe}$ & 2.0 & 1015 & $0.1-10 \mathrm{kHz}$ & $300-575 \mathrm{~K}$ \\
\hline Supermendur & $49 \mathrm{CO}-49 \mathrm{Fe}-2 \mathrm{~V}$ & 2.4 & 1255 & $0.1-10 \mathrm{kHz}$ & $300-575 \mathrm{~K}$ \\
\hline
\end{tabular}

Amomhous Materials

$\begin{array}{llllll}\text { Metglas 2605SC } & \mathrm{Fe}_{81} \mathrm{~B}_{13.5} \mathrm{Si}_{3.5} \mathrm{C}_{2} & 1.6 & 645 & 1.50 \mathrm{kHz} & 300-575 \mathrm{~K} \\ \text { Metglas 2605S-3A } & \mathrm{Fe}_{77} \mathrm{~B}_{16} \mathrm{Si}_{5} \mathrm{Cr}_{2} & 1.4 & 630 & 1-50 \mathrm{kHz} & 300-575 \mathrm{~K}\end{array}$

\section{DISCLAIMER}

This report was prepared as an account of work sponsored by an agency of the United States Government. Neither the United States Government nor any agency thereof, nor any of their employees, makes any warranty, express or implied, or assumes any legal liability or responsibility for the accuracy, completeness, or usefulness of any information, apparatus, product, or process disclosed, or represents that its use would not infringe privately owned rights. Reference herein to any specific commercial product, process, or service by trade name, trademark, manufacturer, or otherwise does not necessarily constitute or imply its endorsement, recommendation, or favoring by the United States Government or any agency thereof. The views and opinions of authors expressed herein do not necessarily state or reflect those of the United States Government or any agency thereof. 


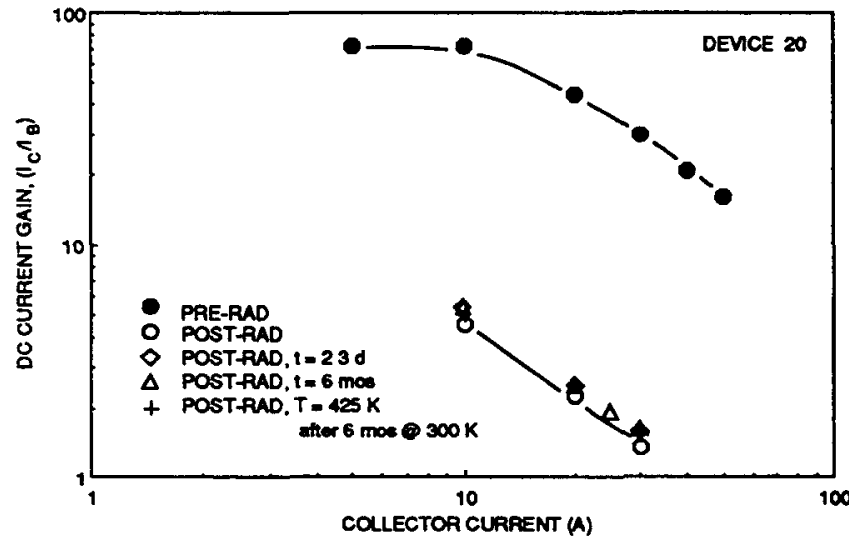

FIGURE 1. DC CURRENT GAIN O VCE -2.5 V VERSUS COLLCTOR CURRENT FOR PRE-IRRADAATION POSTARRADUATON (FLUX $=755 \times 10^{6} \mathrm{ncm}^{2}$, FLUENCE - $165 \times 10^{13} \mathrm{~N}^{\mathrm{cm}}{ }^{2}$. GAMMMA DOSE - $37 \mathrm{kradk}$ ). AND THERMML ANNEENUNG CONDITONS FOR NPN BNT TRANSISTOR D6OT 455010 ALL MEASUREMENTS MADE AT $300 \mathrm{~K}$.

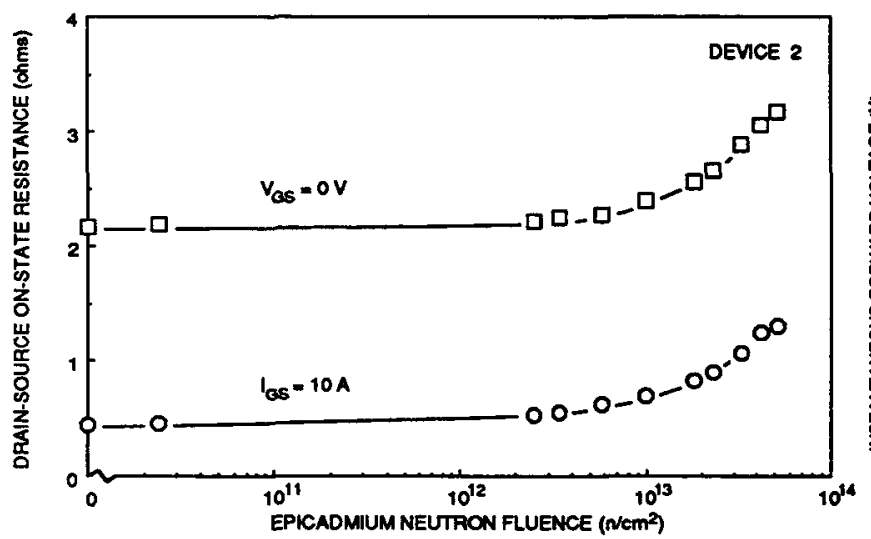

FIGURE 3 DRAIN-SOURCE ONSTATE RESISTANCE FOR ID - 18 A VERSUS EPICADMUUM NEUTRON FLUENCE FOR N-CHANNEL ST $2 S K 180$ (600 V/8 A), NEUTRON FLUX - $755 \times 10^{7} \mathrm{TO}^{3} 78 \times 10^{\circ} \mathrm{NCm}^{2} \mathrm{a}$, GAMMAA DOSE - $94 \mathrm{krada}$

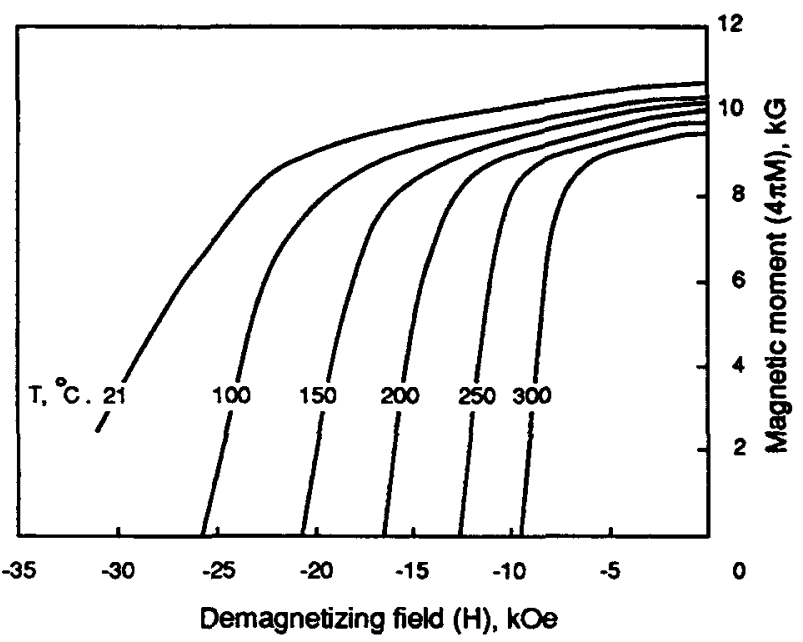

FIGURE 5. DEMAGNETIZATION CHARACTERISTICS OF A COMMERCIAL ANISOTROPIC 2-17 TYPE SAMARIUM-COBALT MAGNET AT SELECTED TEMPERATURES TO $573 \mathrm{~K}$

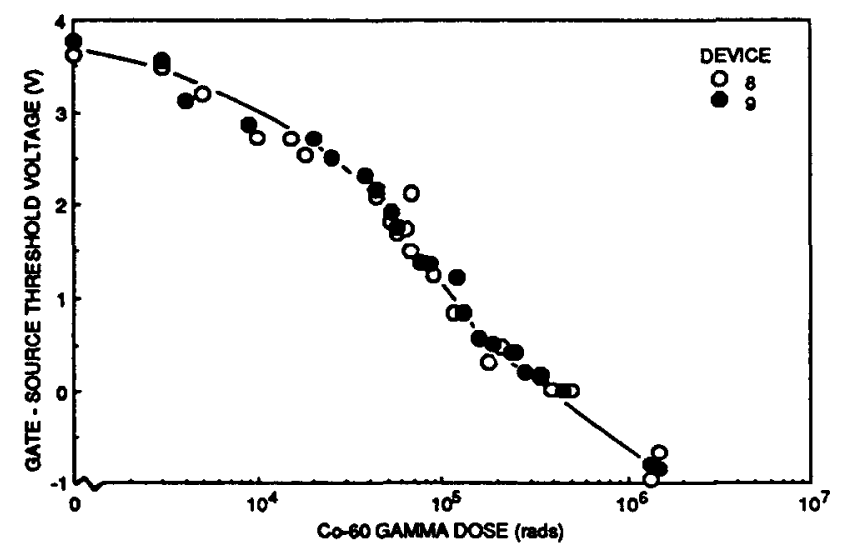

FGUAE 2. GATE-SOUACE THPESHOL VOLTAGE VEASUS GAMMA DOSE FOR $N$ CHANWEL ENHUNCEMENT MOSFET MTMH SNSO (500 V/15 A), GAMMA DOSE RATE = 33.8 TO $621 \mathrm{kr}$. $\mathrm{d} / \mathrm{hr}$

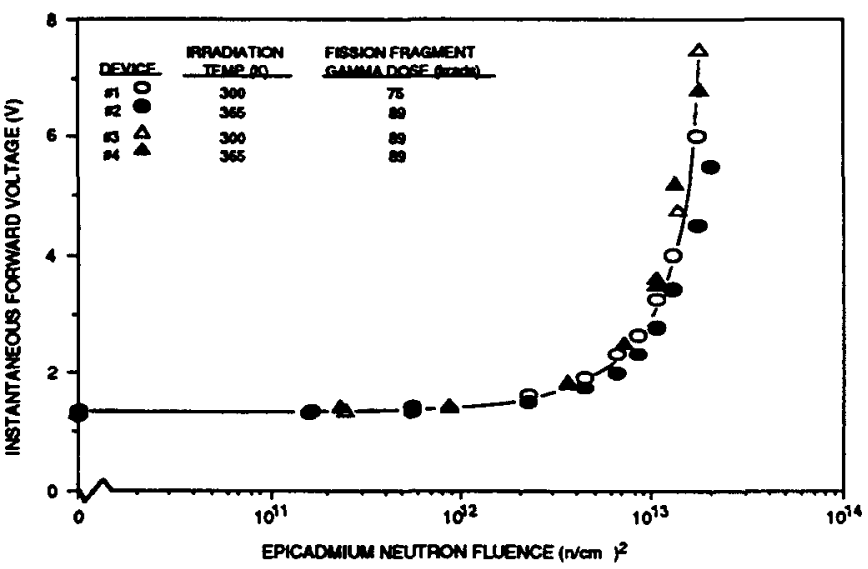

FIGUPE 4 INSTANTANEOUS FORWWAD VOLTAGE AT INSTANTANEOUS FORWARD CURRENT OF 25 A VERSUS EPICADMIUM NEUTRON FUENCE FOR INVERTER TYPE SULCON CONIROLED RECTFIER 2ORFF4OWZO ( $100 \mathrm{~V} / 32 \mathrm{~A})$

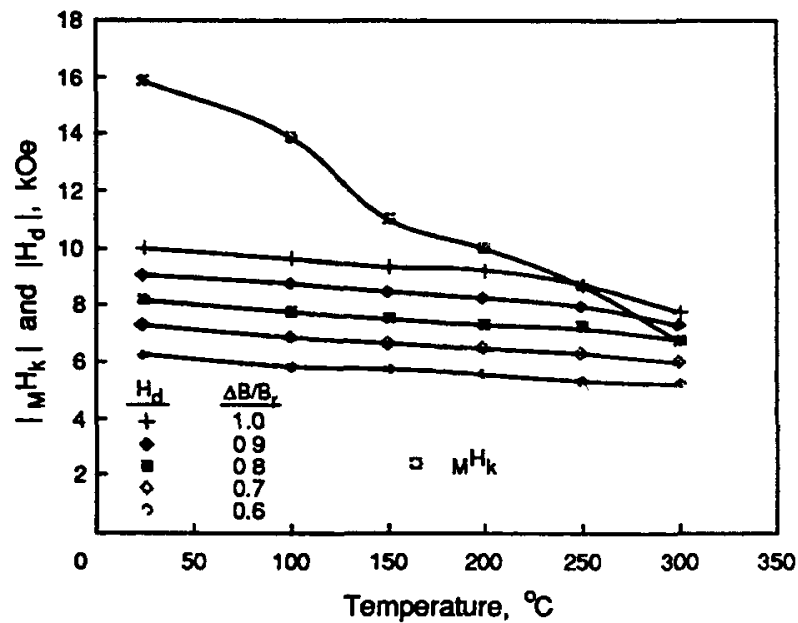

FIGURE 6. VARAATION OF THE KNEE FIELD ( $M$ H) AND THE DEMAGNETIZING

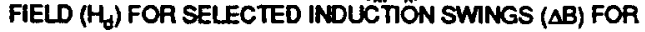
DEMAGNETZZATION CURVES GIVEN IN FIGURE 5. 
Public reporting burden for this collection of information is estimated to average 1 hour per response, including the time for reviewing instructions, searching existing data sources, gathering and maintaining the data needed, and completng and revewing the collection of information. Send comments regarding this burden estimate or any other aspect of this collection of information, including suggestions for reducang this burden, to Washington Headquarters Services, Directorate for intormation Operations and Reports, 1215 Jefferson Davis Highway, Sure 1204, Arlington, VA 22202-4302, and to the Office of Management and Budget, Paperwork Reduction Project (0704-0188), Washington, DC 20503.

1. AGENCY USE ONLY (Leave blank) 2. REPORT DATE

January 1993 3. REPORT TYPE AND DATES COVERED

4. TITLE AND SUBTITLE

Radiation and Temperature Effects on Electronic Components Investigated Under the CSTI High Capacity Power Project

\section{AUTHOR(S)}

Gene E. Schwarze, Janis M. Niedra, Albert J. Frasca, and William R. Wieserman

\section{PERForming ORganitation NAME(S) AND ADdRESS(ES)}

National Aeronautics and Space Administration

Lewis Research Center

Cleveland, Ohio 44135-3191

9. SPONSORING/MONITORING AGENCY NAMES(S) AND ADDRESS(ES)

National Aeronautics and Space Administration

Washington, D.C. 20546-0001
Technical Memorandum

WU-467-01-21

8. PERforming organization REPORT NUMBER

E-7737

10. SPONSORING/MONITORING AGENCY REPORT NUMBER

NASA TM-106096

\section{SUPPLEMENTARY NOTES}

Prepared for the Tenth Symposium on Space Nuclear Power and Propulsion sponsored by the University of New Mexico, Albuquerque, New Mexico, January 10-14, 1993. Gene E. Schwarze, NASA Lewis Research Center; Janis M. Niedra, Sverdrup Technology, Inc., Lewis Research Center Group, 2001, Aerospace Parkway, Brook Park, Ohio 44142; Albert J. Frasca, Wittenberg University, Springfield, Ohio 45501; and William R. Wieserman, University of Pittsburgh at Johnstown, Johnstown, Pennsylvania 15904. Responsible person, Gene E. Schwarze, (216) $433-6117$.

12a. DISTRIBUTION/AVAILABILITY STATEMENT

Unclassified - Unlimited

Subject Category 33

\section{ABSTRACT (Maximum 200 words)}

The effects of nuclear radiation and high temperature environments must be fully known and understood for the electronic components and materials used in both the Power Conditioning and Control subsystem and the reactor Instrumentation and Control subsystem of future high capacity nuclear space power systems. This knowledge is required by the designer of these subsystems in order to develop highly reliable, long-life power systems for future NASA missions. A review and summary of the experimental results obtained for the electronic components and materials investigated under the power management element of the CSTI high capacity power project will be presented in this paper: (1) Neutron, gamma ray, and temperature effects on power semiconductor switches, (2) Temperature and frequency effects on soft magnetic materials; and (3) Temperature effects on rare earth permanent magnets.

\section{SUBJECT TERMS}

Radiation effects; Temperature effects; Semiconductor switch; Radiation damage; Magnetic materials; Permanent magnets; Power conditioning

\begin{tabular}{|c|c|c|}
\hline $\begin{array}{c}\text { 17. SECURITY CLASSIFICATION } \\
\text { OF REPORT } \\
\text { Unclassified }\end{array}$ & $\begin{array}{c}\text { 18. SECUAITY CLASSIFICATION } \\
\text { OF THIS PAGE } \\
\text { Unclassified }\end{array}$ & $\begin{array}{c}\text { 19. SECUATY CLASSIFICATION } \\
\text { OF ABSTRACT } \\
\text { Unclassified }\end{array}$ \\
\hline
\end{tabular}


National Aeronautics and

Space Administration

Lewis Receareh Center

Cleveland, Ohio $\mathbf{4 4 1 3 5}$

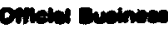

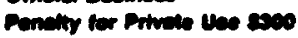

FOUnTH CLASB mall

ADDRESS COARECTION REQUESTED 